$10-1-2018$

\title{
Establishing a Review Process to Evaluate Research Guides
}

\author{
Heather Brown \\ University of Nebraska Medical Center, hlbrown@unmc.edu \\ Danielle Westmark \\ University of Nebraska Medical Center, danielle.westmark@unmc.edu \\ Christian I.J. Minter \\ University of Nebraska Medical Center, christian.minter@unmc.edu
}

Tell us how you used this information in this short survey.

Follow this and additional works at: https://digitalcommons.unmc.edu/mcgoogan_articles

Part of the Library and Information Science Commons

\section{Recommended Citation}

Brown, Heather; Westmark, Danielle; and Minter, Christian I.J., "Establishing a Review Process to Evaluate Research Guides" (2018). Journal Articles: Leon S. McGoogan Health Sciences Library. 8.

https://digitalcommons.unmc.edu/mcgoogan_articles/8

This Article is brought to you for free and open access by the Leon S. McGoogan Health Sciences Library at DigitalCommons@UNMC. It has been accepted for inclusion in Journal Articles: Leon S. McGoogan Health Sciences Library by an authorized administrator of DigitalCommons@UNMC. For more information, please contact digitalcommons@unmc.edu. 
This is an Accepted Manuscript of an article published by Taylor \& Francis in Medical Reference Services Quarterly on 05 Feb 2019, available online:

https://doi.org/10.1080/02763869.2018.1514901

\title{
Establishing a Review Process to Evaluate Research Guides
}

\author{
Heather Brown \\ Danielle Drummond \\ Christian I.J. Minter
}

\begin{abstract}
Springshare's LibGuide platform has become synonymous with online library pathfinders or research guides and instruction support. However, without oversight of the collection of guides and standards for their creation, unwieldy numbers and lack of uniformity prevail. The McGoogan Library of Medicine at the University of Nebraska Medical Center created a review process that not only governed the creation and approval of guides, but analyzed the usage and scope of guides that had already been created. This paper will outline the creation of standards and application of a review process to increase the value and relevance of guides.
\end{abstract}

KEYWORDS. Library guides, LibGuides, pathfinders, research guides, standards

\section{Author Information:}

Heather Brown, MA (hlbrown@unmc.edu) is Head of Collection Services, McGoogan Library of Medicine, University of Nebraska Medical Center, 986705 Nebraska Medical Center, Omaha, NE 68198-6705. 
Danielle Drummond (danielle.drummond@unmc.edu) is Education \& Research Services Associate, McGoogan Library of Medicine, University of Nebraska Medical Center, 986705 Nebraska Medical Center, Omaha, NE 68198-6705.

Christian Minter, MSLIS (christian.minter@unmc.edu) is Community Engagement and Health Literacy Librarian, McGoogan Library of Medicine, University of Nebraska Medical Center, 986705 Nebraska Medical Center, Omaha, NE 68198-6705.

This manuscript was based on a paper presented at the Annual Meeting of the Medical Library Association Annual Meeting, Seattle, WA, May 29, 2017. 


\section{INTRODUCTION}

Pathfinders have long been a tool used by librarians to guide and instruct library users. Pathfinders were paper-based subject guides listing resources to assist library users and as technology evolved, libraries have used electronic means to develop pathfinders. ${ }^{1}$ In the age of the Internet, the University of Nebraska Medical Center's McGoogan Library of Medicine created pathfinders and other instructional materials, which were accessible on the library's website. At that time, knowledge of HTML was necessary and only one or two librarians had access to produce and publish web content, creating a burden on those individuals. Today, Springshare's LibGuide platform has become synonymous with online library pathfinders and instruction support. Debuting in $2007^{2}$ and adopted by McGoogan Library in 2008, LibGuides offered librarians with little to no web design skills the ability to easily produce web-based content.

Due to the ease of use, the McGoogan Library experienced a surge in LibGuide creation over the years. Without any oversight or standards for the collection of LibGuides, now called Research Guides at the library, unwieldy numbers and a lack of uniformity prevailed. At one point, the library had more guides than pages within its website. Content that should have been on the website was placed on guides. There was no a planned lifecycle, and guides were often created and then forgotten. As a result of lack of standardization, the guides had multiple voices and styles, almost as many as the number of individuals creating them. For instance, instructional guides ranged from providing basic, high-level instruction to detailed, step-by-step instruction. A lack of scope prevailed, with no clear definition of what should or should not be a guide and whether guides were relevant to the library's mission. Additionally, there was no process to 
assess whether guides were useful or if audiences were actually using them. One librarian stated, “I feel like I'm creating LibGuides for me. I feel like my students don't look at them.” Finally, rather than considering other more appropriate platforms such as the library's or a partnering departmental website, guides were seen as the first option when web content needed to be created. With a great deal of time put into creating guides, there was concern whether this was an appropriate use of time by guide authors, if the guides met the mission of the library, or if the guides were useful to library users.

These factors were recognized over the years, but it was the migration from LibGuides 1.0 to LibGuides 2.0 that prompted an initiative to create standards and a peer-review process to increase the value and relevance of the library's guides. A new committee was established in 2016 and given supervision of the library's website and guides. The Web Committee was charged with creating an approval and review process for new and existing guides, with the first step being a review of the literature.

\section{LITERATURE REVIEW}

Springshare's LibGuide product can be a reasonably easy to use and useful tool for librarians, especially when needing an online platform to share information with their users. With the number of sections, contained within tabs, and limitless space for content that a single guide can contain, it's easy for an individual LibGuide to get out of control. When reviewed, common themes emerged in the literature related to library guide best practices and standards. These practices and standards generally revolved around design, usability, and impact on the audience. 
Frequent problems found in library guides are lack of consistency (e.g., naming, style, content, organization); lack of upkeep (e.g., broken links and outdated information or resources); and location of guides on a library website (e.g., hidden behind layers of navigation). ${ }^{3}$ Without consistency, design elements tend to vary from guide to guide in a single library. This design issue can cause the problem of library users becoming confused when using a guide, particularly if they are required to refer to multiple guides for different courses or assignments. Furthermore, guides not identifying the audience can impede the reliability of the guide. ${ }^{4}$

Writing for the web and the use of library jargon are other problems found in library guides. Most creators tend to use terms like bibliographic, recall, holdings, etc. Creators often will try to include as much information as possible into a single guide, which brings up the issue of cognitive overload. ${ }^{5}$ People tend to read information differently on an electronic device, compared to print resources, which impacts the usefulness of a library guide. The recommendation is that guide authors keep guides brief and straightforward and that they make use of headers and labels which allow users to find information quickly. ${ }^{6}$ Naming conventions are another critical factor. They can help minimize confusion, clearly identify what the library guides are, and what they can be used for. ${ }^{3}$

There have been a few usability studies conducted on LibGuides, pertaining to how library users interact with them and whether or not they find the tool useful. These studies focused on strengths that libraries can build upon and areas of weaknesses that need to be addressed. One study found that users preferred guides that contained fewer text, made use of bullet points and headings, and required less scrolling. ${ }^{7}$ The use of library jargon, inconsistency, and overuse of tabs were additional barriers encountered by users when evaluated. ${ }^{8}$ Content duplication, inconsistent linking to library databases, and redundant features were also found as 
negatives for users. ${ }^{9}$ Suggested best practice features are to make sure vital content is placed in the first tab of a guide, include interactive content, and not use an overabundance of tabs in a single guide. ${ }^{10}$

When libraries have identified issues with their guides, either through an evaluation or by a usability study, most start to piece together standards or guidelines for guide owners to follow. New Mexico State University's guidelines cover organization, audience, assessment, collaboration, and maintenance, outlining their best practice strategies for their library staff to follow in a straightforward and concise manner. ${ }^{4}$ This set of guidelines allows it to be a working document, adaptable, and unrestricted to guide owners. Kansas State University librarians note that it is important to make sure library staff understand the new policies to help ease any apprehensions that staff might have and to emphasize that the intent of new policies is for design, not content restriction. ${ }^{11}$

Implementation of standards into the workflow of guide creation is an additional recommendation mentioned in the literature. To help make sure that standards are being met, some form of leadership is usually established. For instance, a single person, or a small group, within the library, acts as a coordinator who works with guide owners. ${ }^{6}$

While not every library has implemented best practices or standards for guides, the literature does show the usefulness of having them in place. Standards can be appropriate guidance that assists with directing the creator in making sure that the content can be read and digested by their audience, that links to outside resources are working properly, and that there is consistency among all guides.

\section{PROCESS}


Before the Web Committee at McGoogan Library was formed, a culling of the guides took place in preparation for the migration from LibGuides 1.0 to LibGuides 2.0. This process was undertaken by the Education \& Research Services department, whose members created most of the guides. At the beginning of the process, 120 guides existed. At the end, 18 guides were made private for possible future use or deletion, 24 were unpublished and scheduled for possible deletion, and 78 remained published. Once the migration was completed, the group recognized the need for increased oversight of guides going forward, and the Web Committee was formed. The Head of Collection Services, who was also the library's webmaster and former LibGuides administrator, chaired the committee, and five additional members represented the Education \& Research Services, Collection Services, and Special Collections departments. Members were recruited based on previous experience with guides and web-based technologies.

The Web Committee's first step was to define the purpose and scope of the guides. This step was taken to ensure all guide creators understood the goal for guides and had a framework in which to work. To define the purpose and scope of guides, the committee members participated in a " 15 words" exercise. Each member contributed a sentence of 15 words or less, which described the role and scope of guides. The key themes from each statement were combined to create one brief statement. The committee borrowed this exercise from a CAP (Change Acceleration Process) and Work Out ${ }^{\mathrm{TM}}$ workshop that library staff had attended in 2015. Developed by General Electric, CAP \& Work Out ${ }^{\mathrm{TM}}$ provides a framework to facilitate change and tools for effective team-based decision-making. ${ }^{12}$

The final purpose and scope as defined by the committee is that "Research Guides contain current, relevant, and curated information that assist the user in meeting a specific 
information need or objective and which support courses and provide instruction on information resources and information literacy." This statement is included in the standards for guide creators and helps lead decisions on whether new topics for guides are appropriate or if existing guides are still relevant.

The committee also reviewed best practices of peer institutions that had written standards for web content. Based on work created and shared by the library at Kansas State University, two guiding documents were created. The "Research Guide Standards"13 assists guide creators in writing for the web and provides procedures for consistency, accessibility, use of multimedia, and the process for using guides as part of a curriculum. The "Research Guide Checklist"14 provides a list of best practices in a brief bullet point format. Items on the list relate to design format and structure, accessibility, writing conventions, and copyright permissions. Both documents are used by the guide creators and committee members providing peer review of new guides.

The committee then created two online submission forms using the Springshare product LibWizard and posted the links to the library's Intranet site. The first form was to be used by guide creators to submit a proposal for a new guide. It included the guide objective, a summary of planned content, and a rationale for why the content should not be incorporated into an existing guide or library web page. When the form is submitted, results are emailed to the entire committee, and committee members have one week to respond. After a new guide is approved and created, the creator makes the guide private and utilizes a second form to request further peer review. The form includes the name and link to the guide, which remains private until peer review is complete. All committee members receive the submission form results, and one member is assigned to each guide to conduct the review. The reviewers have two weeks to check 
the guide against the standards. The creator will receive an email with feedback. Once any necessary modifications are made, the research guide is made public. Guides created for specific courses do not need to go through the initial approval process; however, they do go through the peer review for standards. The committee recognizes the expertise of the guide authors and does not critique the content. The standards check focuses on how the content is presented for the end user and ensures that guides adhere to web and accessibility standards. It should be noted that the LibGuides CMS platform, which the library licenses, has a publishing workflow built in, which mirrors the committee's process. However, part of that workflow prevents guide creators from adding new components to existing guides without approval. The committee decided at the onset of process creation that the workflow was too restrictive. However, the committee may revisit the built-in workflow in the future.

At this time, five guides have been submitted and approved for creation, and seven guides have been reviewed based on the standards. Only one guide has not been approved at this time. The proposed guide would have been a list of productivity tools created for a one-time use to support a specific course. The committee recommended that the list should be incorporated into an existing guide or added to the course site within the university's learning management system.

The next step in guide oversight was to address the use of private or unpublished guides. Some library faculty and staff were using private guides as a sandbox or personal storage space for resources they intended to use for future instruction activities. Referring back to the purpose statement that guides are created to assist library users in meeting an information need or to support courses, the Web Committee decided that this was not the appropriate web space for personal files and links. Furthermore, sandbox components could be added to respective guides and made hidden from the public. The committee reviewed all private and unpublished guides 
and decided to eliminate their use as sandboxes going forward. Guide authors received instructions on how to archive content and recommendations for other options to store links and instructional content. Approximately 20 private and unpublished guides were removed.

Next, the committee conducted a review of public guides based on usage and scope to determine which guides should be retired or have its content incorporated elsewhere. Two waves of reviews based on usage occurred, first with guides that had received less than 20 views within the last year, then those that received less than 30 views. Guide creators were asked to delete them or consolidate the content into another guide, library web page, or FAQ. Authors had the opportunity to appeal this decision if they felt the guide was still needed despite low usage. Eleven guides were removed or incorporated into other guides or web pages.

Guides that had received higher views were reviewed by the committee to identify duplication with other guides, to determine if the content was still relevant to the intended audiences, and to distinguish content which would be more appropriately hosted on other websites at UNMC. Using a spreadsheet, each committee member indicated if a guide should be removed for one of the reasons listed above. The group decisions were mostly unanimous. Eighteen guides were identified and either removed or incorporated into other guides or website pages.

Currently, the committee has started the process of taking the remaining 35 guides which were created before the peer review process through a standards check. Guide creators will be notified when their guide is up for review. They will have the opportunity to check their guides first and make any updates to bring them into compliance with the new standards. Then the committee will conduct a final review and provide feedback if needed. The committee is also 
working on creating a strategy for guide maintenance to minimize broken links or outdated content.

With the assistance and support of department supervisors, reception of the new processes and oversight was met with little opposition. There has been some confusion over whether guide creators need permission to update or edit an existing guide. After a guide is approved and checked against standards, the creator is free to update as needed. There have been instances in which guide creators have forgotten to include the peer-review process in their workflow, such as when course guides need to go through a standards check despite not needing approval for creation. When the committee becomes aware of this, they send a reminder to the guide creator about the standards. The committee gives guide creators ample time to phase out guides, though follow-up regarding requests to remove guides has had to take place.

\section{CONCLUSION}

At present, the library has 36 public guides. This project has helped to address an unruly collection of web content and encourage guide creators to ask the questions: "Does this need to be a LibGuide?" "Should it be something else?" "Does this need to live on our website?" Library users are faced with a large amount of information on library web platforms, from online resources, policies, and instruction. By creating a review process for potential guides and reviewing existing guides, the information conveyed to library users on this platform has become more manageable and condensed. While the rate of guide creation has decreased as a result of the approval process, the content and scope of guides has increased in its relevance to library users. Furthermore, course-based guides are not required to go through the approval process, and 
guide creators have the freedom to determine that content. The primary objective of this process is to facilitate the most appropriate platform for web-based content. Further research would be needed to determine how library users are affected by these changes or their use of guides.

Received: May 30, 2018

Revised: July 11, 2018

Accepted: July 20, 2018

\section{REFERENCES}

1. Wikipedia. "Pathfinder (Library Science)." Accessed July 6, 2018.

https://en.wikipedia.org/wiki/Pathfinder_(library_science).

2. Springshare. “About Springshare.” Accessed March, 28, 2018.

https://www.springshare.com/about.html.

3. Morris, Sara E., and Darcy Del Bosque. "Forgotten Resources: Subject Guides in the Era of Web 2.0." Technical Services Quarterly 27, no. 2 (2010): 178-193.

4. Gonzalez, Alisa C., and Theresa Westbrock. "Reaching Out with LibGuides: Establishing a Working Set of Best Practices." Journal of Library Administration 50, no. 5-6 (2010): 638656.

5. Baker, Ruth L. "Designing LibGuides as Instructional Tools for Critical Thinking and Effective Online Learning." Journal of Library $\mid \&$ Information Services in Distance Learning 8, no. 3-4 (2014): 107-117. 
6. Puckett, Jason. Modern Pathfinders: Creating Better Research Guides. Chicago, IL: Association of College and Research Libraries, 2015.

7. Conerton, Kate, and Cheryl Goldenstein. "Making LibGuides Work: Student Interviews and Usability Tests.” Internet Reference Services Quarterly 22, no. 1 (2017): 43-54.

8. Sonsteby, Alec, and Jennifer DeJonghe. "Usability Testing, User-Centered Design, and LibGuides Subject Guides: A Case Study.” Journal of Web Librarianship 7, no. 1 (2013): 83-94.

9. Almeida, Nora, and Junior Tidal. "Mixed Methods Not Mixed Messages: Improving LibGuides with Student Usability Data.” Evidence Based Library \& Information Practice 12, no. 4 (2017): 62-77.

10. Castro Gessner, Gabriela, Adam Chandler, and Wendy Sue Wilcox. "Are You Reaching Your Audience? the Intersection between LibGuide Authors and LibGuide Users." Reference Services Review 43, no. 3 (2015): 491-508.

11. Fritch, Melia, and Joelle E. Pitts. "Adding Bite to the Bark: Using LibGuides2 Migration as Impetus to Introduce Strong Content Standards.” Journal of Electronic Resources Librarianship 28, no. 3 (Jul, 2016): 159-171.

12. Kieffer, Jim. Change Agent Training: CAP (Change Acceleration Process) and Work Out ${ }^{\mathrm{TM}}$. taff development workshop presented at the McGoogan Library of Medicine, Omaha, NE, December 20152015.

13. "Research Guide Standards.” Accessed March 28, 2018. http://webmedia.unmc.edu/library/brown/guidestandards.pdf. 
14. "Research Guide Checklist.” Accessed March 28, 2018. http://webmedia.unmc.edu/library/brown/guidechecklist.pdf. 